\title{
Conservation Biology and Traditional Ecological Knowledge: Integrating Academic Disciplines for Better Conservation Practice
}

\author{
$\underline{\text { Joshua A. Drew }}^{1}$ and $\underline{\text { Adam P. Henne }}^{2}$
}

\begin{abstract}
Conservation biology and environmental anthropology are disciplines that are both concerned with the identification and preservation of diversity, in one case biological and in the other cultural. Both conservation biology and the study of traditional ecoloigcal knowledge function at the nexus of the social and natural worlds, yet historically there have been major impediments to integrating the two. Here we identify linguistic, cultural, and epistemological barriers between the two disciplines. We argue that the two disciplines are uniquely positioned to inform each other and to provide critical insights and new perspectives on the way these sciences are practiced. We conclude by synthesizing common themes found in conservation success stories, and by making several suggestions on integration. These include crossdisciplinary publication, expanding memberships in professional societies and conducting multidisciplinary research based on similar interests in ecological process, taxonomy, or geography. Finally, we argue that extinction threats, be they biological or cultural/linguistic are imminent, and that by bringing these disciplines together we may be able to forge synergistic conservation programs capable of protecting the vivid splendor of life on Earth.
\end{abstract}

Key Words: anthropology; conservation; critical analysis; multidisciplinary research.

\section{INTRODUCTION}

Conservation biology has often been called a crisis discipline (Pullin 2002, Wilson 2002). Its focus on rapidly altering ecosystems, biological extinctions, and the ultimate loss of biodiversity defines a discipline that lacks the luxury of time (Chapin III et al. 2000). Species are going extinct before they have the chance to be recognized, while fewer and fewer places on Earth represent fully functioning ecosystems (May 1994, McCann 2001).

Although the discipline is relatively new, arising in earnest in the late 1970s, the urgent nature of the threats, coupled with the larger societal increase in environmental awareness, has caused the practice to grow at an exceptional rate. There are now multiple journals dedicated towards conservation, and the Society of Conservation Biology has over 5000 members.

Anthropologists too deal with rapidly changing systems. Whereas conservation biologists deal with biological extinctions, anthropologists who study the relationship between indigenous or traditional societies and their natural environment are often faced with the erosion of linguistic or other cultural practices (Berlin 1992, Sutherland 2003). The study of human culture's dynamic interactions with local environments predisposes anthropologists in this subdiscipline toward an understanding of natural resource use. The terminology in this context is hotly contested (see Agrawal 1995 or Ellen and Harris 2000 for genealogical and analytical discussions of these terms). Current research frequently addresses environmental transformations, development projects, and cultural continuity and change (Berlin 1992, Stearman and Redford 1994, Warren et al. 1995, Nazarea 1998, Silvano and Begossi 2002). We have chosen to use "traditional ecological knowledge" (TEK) in part because this is the predominant usage among conservationists, and in part to avoid confusion with specifically indigenous concerns around religious practices or intellectual property rights.

Throughout much of the 1980s and early 1990s, conservation biology focused on "fortress" methods 
of conservation (Dugan and Davis 1993, De Vires 1995, reviewed in Sloan 2002). Humans were seen as the ultimate cause of environmental degradation; therefore, by sequestering large tracts of land and removing human populations, "natural" areas could be "saved."

Although there is still a lively debate in the literature, most researchers now recognize that the social context and social impacts of conservation are critical factors (Vieitas et al. 1999, Schwartzman et al. 2000, Johannes 2002). Programs that garner support of the affected peoples tend to survive, whereas those that adopt a cavalier attitude toward local peoples face significant challenges toward maintaining long-term sustainability (Bowen-Jones and Entwistle 2002).

The anthropology of traditional ecological knowledge (TEK) also takes place in a changing landscape. Because their research focuses on the nexus of human and natural interactions, these anthropologists must deal with ways in which rapid and irreversible changes in the natural environment can cause complex, nonlinear, changes in human societies (Ernst 1999, Diamond 2004). Conservation biology is in a position to add substantive information to such research because of an existing methodological, operational, and philosophical framework to address the biological aspects of these multifaceted problems (see Calamia 1996, Ross and Pickering 2002 for examples). Furthermore, conservation biologists are blessed with relatively good access to funding resources and political influence through states and international NGOs. This is an aspect of collaboration that no social scientist can afford to overlook.

However, because conservation biologists are often ill equipped to understand the complexities of human cultural interactions with the natural environment, anthropologists of TEK are in a position to offer advice. We suggest that the two disciplines, conservation biology and anthropology, are uniquely positioned to strengthen each other's work, and that the two form a potentially valuable union. Why then, do we not see more formalized collaborative efforts between them?

\section{REASONS FOR THE DISCONNECT}

To understand how we can bring conservation biology and the anthropology of traditional ecological knowledge (TEK) together, we first need to understand some of the reasons the two disciplines have not worked closely in the past, in particular, for three major reasons: difficulties in communication, cultural differences, and different epistemological origins. By more closely examining these causative agents, it is our hope that we can reconcile these disparate disciplines.

\section{Communication difficulties}

Most researchers find themselves under tremendous time constraints; too often staying abreast of the current literature falls to the wayside under the constant pressure from faculty meetings, tenure evaluations, report deadlines, and teaching responsibilities (Campbell 2005). Because of these time constraints, few researchers find the time to read through literature within their discipline, let alone those journals that lie outside their academic purview. Therefore, many conservation biologists do not have the time to read potentially relevant social science research, provided they would even know where such data lie, and vice versa. These factors leave cross-disciplinary publication as one of the few avenues by which a researcher might be exposed to other academic disciplines.

As language serves to bind a community together, it also serves to exclude those not part of that community. Publication in peer-reviewed media is the currency of scientific discourse, and when that publication is based on specific lexicon, we can experience a discursive failure. When one publishes in a journal there is an assumption of a shared specific body of knowledge, which often is based on, or at least expressed in, very discipline-specific language. These languages can consist of obscure words,. e.,g., hirsute, discipline specific words not appearing in the larger language, e.g., euryhaline or, perhaps most confounding, words that have different meanings within the discipline than in the general language, e.g., parsimonious. Because many scientists publish using a ritual cadence and form, it is difficult for one not trained in that language to understand the nuances of the research, or to participate within those journals. 


\section{Cultural differences}

Cultural differences in publication and career advancement also serve to continue the disconnect between conservation biology and most subfields of anthropology. In general, anthropologists seeking tenure at academic institutions are encouraged to publish their findings in books and peer-reviewed journals (P. West, personal communication).

For a biologist in a similar situation, it is suggested that research be published primarily in peerreviewed journals. Because many fields in biology are rapidly changing, most biologists put a premium on new research findings, thus few would think to look in a book for the most current information because of the editing and turn-around time required for its publication.

Moreover, within academic communities there is an awareness of varying levels of prestige ascribed to journals, which is difficult to estimate outside one's academic field (Campbell 2005). Therefore, to ensure the maximum return on their publications, most young researchers tend to publish in venues that will best advance their careers. Thus, we have established a system that actively and methodically serves to discourage young researchers from publishing outside of their academic field.

\section{Different epistemological origins}

Although they may have similar goals, conservation biology and the anthropology of traditional ecological knowledge (TEK) developed from drastically different disciplinary histories and depend on widely variant philosophical bodies of knowledge. As a subfield of anthropology, the study of TEK also draws on economic botany, linguistics, and archaeology (Clement 1998, Ellen and Harris 2000 and Zent, personal communication). Conservation biology has its roots in forestry, ecology, and game management (Meffe and Carroll 1997). Thus, whereas both sciences deal with rapidly changing systems, and focus on the interactions between humans and nature, they address these issues with different epistemological lenses.

The diverse data types used by anthropologists and biologists stem from different approaches toward discovery. The distinct approaches favored by scientists from the two fields can be described according to linguist Kenneth Pike's categories of emic vs. etic knowledge (Headland et al. 1990). An etic perspective seeks to understand a phenomenon from an outsider's position, privileging those data drawn from empirical observation, operationalized definitions, and replicable situations. A researcher working toward an emic understanding, on the other hand, seeks to understand the phenomenon from the perspective of the participants, according to their own unique and culture-bound definitions (Headland et al. 1990).

Whereas few research plans could be described as entirely one or the other, the disciplines under discussion show a distinction in their positioning on the issue. The process of eliciting emic understanding of natural environments, and translating these understandings into a language comprehensible to an outside audience, is the mission that puts the "ethno" into an anthropologist's ethnographic study. Conservation biologists, on the other hand, are steeped in the doctrines and practices of positivism, and often deal with more quantitative and discrete forms of etic data.

These epistemological differences lead to distinct methodologies, as part of each disciplines particular history. An anthropologist studying TEK, like any cultural anthropologist, is heir to that disciplines' tradition of subjective, qualitative learning and reflexive self-criticism. Anthropology's classical methods, such as participant observation and immersive ethnography, have gradually expanded to include deconstructions of culture, gender, nature, and other textual discourses. As postcolonial peoples began to assert their roles in describing and defining culture, anthropology was forced to adopt a self-analytical perspective. This reflexive pose includes an awareness of the role the scientist plays in contributing to culture change, and accountability for the results of anthropological definitions of culture.

These subjective research practices run counter to the traditions within the physical and life sciences of empirical testing of null hypothesis with multiple controls. As such, conservation biology publications rarely acknowledge the potential social impact of science, especially on indigenous or marginalized peoples. Because of their desire to remain objective from the study, many biologists feel uncomfortable participating in larger, more reflexive critiques of 
their disciplines impacts both direct, i.e., the study site, but also indirect effects on local people's economies (See West 2006). Fortunately selfcriticism is starting to make an entrée into the conservation biology landscape (Robertson and Hull 2001, Song and M'Gonigle 2001). Although this is a heartening trend, conservation biology still has much to learn as it develops into a more inclusive, and ultimately a more robust, discipline (Mascia et al. 2003).

\section{BRINGING IT TOGETHER}

Both anthropology and conservation biology as disciplines need to engage each other intellectually, to identify common research interests, and to pursue them in an equitable, multidisciplinary fashion. These common research interests could be process driven, e.g., researchers interested in the impacts of invasive species on natural resource use, taxa driven, e.g., collaborators interested in the plant family Solanaceae, or they could be geographically driven, e.g., people interested in working in Antongil Bay in Madagascar. Regardless of which kind of interest is shared, identifying that interest is the first step toward forging a productive collaboration. How then to identify common research interests? Below, we have identified some actions that researchers in one discipline can take to foster multidiscipline collaborations.

\section{Anthropology integrated with conservation biology}

Conservation biology, as a discipline, is now beginning to recognize that the culture and cultural diversity are among the most critical factors in the ultimate success of a conservation regime (Huntington 2000, Pollnac et al. 2001, Hickey and Johannes 2002, Johannes 2002, Kramer et al. 2002). However, most conservation biologists received their academic training through biology departments, and few are well equipped to collect or analyze qualitative data on human societies despite those data being an understudied component of successful management (Pierce Colfer et al. 1999, Huntington 2000). Conservationists increasingly realize the need for critical analyses of human-mediated environmental impact (Curran et al. 2002); scholars bringing new perspectives from traditional ecological knowledge are therefore likely to find a willing audience in conservation biologists.
Intellectual parochialism serves to keep potential collaborators apart, and any attempts by anthropologists to breach that should be commended.

To best bridge the divide, anthropologists working with TEK should seek to be more involved in groups such as the Ecological Society of America (ESA) or the Society of Conservation Biology (SCB). The latter organization has made significant steps toward the kind of collaborative work we describe with the founding of the Social Science Working Group in 2003 http://www.conbio.org/workinggroups/ SSWG/. By participating in these societies, including attending annual meetings, anthropologists can build a strong network of potential collaborators, become informed of the latest techniques being developed and participate in the debates within the larger conservation biology community.

In a similar fashion publishing within the conservation biology journals provides an effective means to disseminate not only one's specific findings, but also the kinds of work being done on traditional ecological knowledge (TEK) as a whole. Both the Society for Conservation Biology (SCB) and the Ecological Society of America (ESA) publish peer-reviewed journals, e.g., Conservation Biology and Ecological Applications, member newsletters and applied journals geared toward nonacademic practitioners, e.g., Conservation in Practice and Frontiers in Ecology and Evolution. These publications provide additional opportunities for anthropologists to raise awareness of the kinds of work they do, as well as representing excellent forums for a unique perspective on on-going conservation dialogues.

\section{Conservation biology integrated with anthropology}

Despite gains made over the past decade and a half, conservation biologists still need to improve their recognition and integration of the human element into conservation programs. A change in perception is needed, from a mindset that sees humans only as the cause of environmental degradation, toward one that recognizes human society's role in the production of what we consider "natural" (Jackson 2001). When conservation biologists come to see that cultural diversity is inexorably linked to biological diversity (Atran et al. 2002), and that 
support of one can offer benefit toward the other (Kirsch 2001, Drew 2005), then the role of the social sciences will become apparent.

Conservation biology is a meta-term, encompassing a variety of different practices, ranging from genetics to geochemical analysis (Meffe and Carroll 1997, Robertson and Hull 2001, Drew 2005). Because of the diversity of topics subsumed by the title it can be difficult to understand what exactly is meant by the term. This debate about how to define conservation biology is not limited to those outside the discipline. As one would expect for such a young field, conservation biologists are still trying to understand who they are and what role they have to play in the larger scientific hierarchy.

This ambiguity about what it means to be a conservation biologist offers a false appearance of exclusion. Most conservation biologists would agree that if one is actively seeking to understand the impacts of humans on natural systems, no matter how broadly defined, and the role those impacts play in the maintenance of biodiversity, then one is doing the work of conservation biology regardless of the disciplinary tools used to conduct the research (Robertson and Hull 2001). Despite this, the majority of active conservation biologists have been trained as biologists, and the kinds of articles they published reflect that. In order to be more inclusive, conservation biologists should seek to make their findings more broadly applicable (Robertson and Hull 2001). This could include publishing results in anthropology journals, participating in anthropological societies, and seeking to work in a multistakeholder, multidisciplinary collaborative fashion (Dight and Scherl 1997, Kremen et al. 1998, Wilkie and Godoy 2001, Mascia et al. 2003).

\section{PUTTING IT TO WORK}

Despite the challenges we have outlined previously, we believe that working in a multidisciplinary context can make it possible to achieve conservation success. There is a small but growing body of literature presenting case studies in which natural and social scientists have joined together and supplemented each other's knowledge bases to produce synthetic and innovative conservation successes. Furthermore, it is encouraging to note that these successes can be found in systems as diverse as South African coastal regions (Harris 2003) coastal Canadian forests (Scientific Panel for
Sustainable Forest Practices in Clayoquot Sound 1995, Braun 2002), dry forests of Madagascar (Loudon et al. 2006) and high Artic environments (Huntington 2000).

These studies deal with a wide variety of conservation scenarios; however, several overarching themes make them applicable to a broader audience. First, many of the conservation problems are exacerbated by poor communication regarding the conservation status of a protected area. By contrast, highlighting the endemic nature of species or rarity of ecosystems can lead to increased feelings of pride and tenure over the success of an area on the part of local communities (Loudon et al. 2006). Helping to develop local constituencies for conservation is a project well-suited to anthropologists who work with traditional ecological knowledge (Mascia et al. 2003, Agrawal 2005). Second, these studies all emphasize the importance of engaging local communities at a variety of stages in the conservation process. Although stressing "local involvement" has become commonplace in conservation literature, actual examples of engagement are relatively rare. These projects have benefited from the involvement of a variety of community stakeholders in the policy-making process, particularly through the use of representative governing councils (Braun 2002, Harris 2003). In both circumstances, anthropologists in their liminal role as "culture brokers" can facilitate the smooth interaction of stakeholders from diverse backgrounds.

A closely related theme in these success stories is the use of empirical science to demonstrate conservation success. In the case of the South African mussels, when conservation scientists set up harvesting intensity plots, including adequate controls, local people had clear evidence that current levels of exploitation were unsustainable (Harris 2003). There is a sometimes a sense that science is used as a tool to disenfranchise local people, particularly when it comes to resource exploitation. By making conservation science more transparent, collaborations between social and biological scientists can help offset this perspective.

An additional benefit of community involvement with experiments and/or natural resource management is the educational and employment opportunities they afford local peoples. In many Fijian communities, for example, working with conservation NGOs is considered a profitable and 
prestigious job (Drew, personal observation) and in many cases assisting with research can lead to broadened educational horizons. Distributing these and other material benefits of conservation research, however, can lead to an infinite variety of social complications (West 2006). The participation of anthropologists, with their holistic perspective on local systems of value and power, can help conservation projects achieve more equitable distribution of benefits.

Finally, these success stories all have been based on extensive meetings with local people, often at the village level. These meetings provide an opportunity for a free-flowing exchange of ideas, information, and equalizing power dynamics between researchers and local peoples. In Papua New Guinea, for example, community involvement and perceived legitimacy of a marine reserve was shown to be the single largest factor in that reserve's success (Cinner et al. 2005a,b).

Moving to a more generalized scale, then, we see one final overarching theme that unifies successful examples of collaborative conservation. In each case, significant time was spent developing meaningful relationships with local people; time to explain the conservation situation and its local pertinence, time to learn about local concerns and their bearing on conservation. This is a timeframe uniquely suited to the traditional methods of anthropological fieldwork, with its emphasis on cultural immersion over long periods.

The argument for long-term research and investing time with local communities may seem to run counter to the "crisis discipline" mentality of conservation. Based on the material that we have discussed here, however, here we argue that the crisis discipline lacks discipline. Although we do not want to downplay the immanency of extinction threats, we do suggest that a meaningful investment of time at the outset of a conservation program will lead to much larger benefits down the line, in terms of clarity, equity, and successful conservation outcomes.

\section{SUMMARY}

In this paper we have attempted to show that conservation biology and the anthropology of traditional ecological knowledge (TEK) form an auspicious union, yet that this union has not been fully realized due to several factors. Fundamentally, the two disciples suffer from past historical ghosts, their differences run deep, and those differences in data kinds, analyses, and philosophical approaches toward research reflect the different academic origins. Furthermore, current systems of tenure evaluation and job promotion continue these impediments toward cross-publication.

To rectify this disconnect, practitioners in both disciplines need to seek innovative collaborations based on areas of similar research interest. Anthropological work on TEK will find an appreciative audience in conservation biology meetings and journals, whereas conservation biologists need to continue to recognize the interactions between humans, culture, and nature and more clearly define what it means to be a conservation biologist.

By forming multidisciplinary projects, researchers can produce "Value Added Conservation" projects, representing the greater intellectual depth and breadth gained by including researchers from a variety of fields into larger research plans. The value of these collaborations has been recognized by a variety of funding agencies that are seeking projects with a broader impact on society (Campbell 2005).

The world's problems are too complex, and the threats are too immanent to work alone. Only by joining together will we be able to truly understand the interactions between people, culture, and nature. Although anthropologists and conservation biologists often work on similar problems, they have too often failed to address these problems in a synthetic fashion. Unfortunately, the disappearance of diversity be it biological, cultural, or linguistic, represents a dulling of the world within which we live. If we decide that this diversity is worth saving, then it is imperative that we record it and analyze what is causing it to disappear. By integrating conservation biology knowledge with results from anthropological studies of the knowledge preserved by local or indigenous communities, we can develop more rigorous tools for both of these tasks.

Responses to this article can be read online at: http://www.ecologyandsociety.org/voll1/iss2/art34/responses/ 


\section{Acknowledgments:}

This paper originated as a class assignment for Paige West's Political Ecology class offered at Columbia University/Barnard College. This manuscript was improved by the thoughtful comments provided by J. Shaffer and the attendees of the 2003 Society for Ethnobiology and 2003 Society for Conservation Biology annual meetings. Comments from three anonymous reviewers greatly helped in improving the quality and scope of this paper. We are also extremely thankful for financial support of the Resilience Alliance (publisher of Ecology and Society).

\section{LITERATURE CITED}

Agrawal, A. 1995. Dismantling the divide between indigenous and scientific knowledge. Development and Change 26:413-439.

Agrawal, A. 2005. Environmentality: technologies of government and the making of subjects. Duke University Press, Durham, North Carolina, USA.

Atran, S., D. Medin, N. Ross, E. Lynch, V. Vapnarsky, E. Ucan Ek', J. Coley, C. Timura, and M. Baran. 2002. Folkecology, cultural epidemiology, and the spirit of the commons. Current Anthropology 43:421-450.

Berlin, B. 1992. Ethnobiological classification: principles of categorization of plants and animals in traditional societies. Princeton University Press, Princeton, New Jersey, USA.

Bowen-Jones, E., and A. Entwistle. 2002. Identifying appropriate flagship species: the importance of culture and local contexts. Oryx 36:189-195.

Braun, B. 2002. The intemperate rainforest: nature, culture, and power on Canada's west coast. University of Minnesota Press, Minneapolis, Minnesota, USA.

Calamia, M. A. 1996. Traditional ecological knowledge and geographic information systems in the use and management of Hawaii's coral reefs and fishponds. High Plains Applied Anthropologist 16 :144-164.

Campbell, L. 2005. Overcoming obstacles to interdisciplinary research. Conservation Biology 19:574-577.

Chapin III, F. S., E. S. Zavaleta, V. T. Eviner, R. L. Naylor, P. M. Vitousek, H. L. Reynolds, D. U. Hooper, L. S., O. E. SalaI, S. E. Hobbie, M. C. Mack, and S. Díaz. 2000. Consequences of changing biodiversity. Nature 405:234-242.

Cinner, J. E., M. J. Marnane, and T. R. McClanahan. 2005a. Conservation and community benefits from traditional coral reef management at Ahus Island, Papua New Guinea. Conservation Biology 19:1714-1723.

Cinner, J. E., M. J. Marnane, T. R. McClanahan, and G. R. Almany. 2005b. Periodic closures as adaptive coral reef management in the Indo-Pacific. Ecology and Society 11 [online] URL:

http://www.ecologyandsociety.org/vol11/iss1/art31/

Clement, D. 1998. The historical foundations of ethnobiology (1860-1899). Journal of Ethnobiology 18:161-187.

Curran, S., A. Kumar, W. Lutz, and M. Williams. 2002. Interactions between coastal and marine ecosystems and human population systems: perspectives on how consumption mediates this interaction. Ambio 31:264-268.

De Vires, M. F. 1995. Large herbivores and the design of large-scale nature reserves in Western Europe. Conservation Biology 9:25-33.

Diamond, J. 2004. Collapse: How societies choose to fail or succeed. Viking Adult, New York, New York, USA.

Dight, I. J., and L. M. Scherl. 1997. The International Coral Reef Initiative (ICRI): global priorities for the conservation and management of coral reefs and the need for partnerships. Coral Reefs 17:139-147.

Drew, J. A. 2005. The Use of traditional ecological knowledge in marine conservation. Conservation Biology 19:1286-1293 
Dugan, J. E., and G. E. Davis. 1993. Applications of marine refugia to coastal fisheries management. Canadian Journal of Fisheries and Aquatic Sciences 50:2029-2042.

Ellen, R., and H. Harris. 2000. Introduction. Pages 1-34 in R. Ellen, P. Parkes, and A. Bicker, editors. Indigenous environmental knowledge and its transformations. Harwood Academic, Amsterdam, The Netherlands.

Ernst, T. M. 1999. Land, stories and resources: discourse and entification in Onabasulu modernity. American Anthropologist 101:88-97.

Harris, J. 2003. Mind over mussels: rethinking Mapalane Reserve. Pages 174-181. World resources 2002-2004: decisions for the Earth: balance, voice, and power. World Resources Institute, Washington, D.C., USA.

Headland, T. N., K. L. Pike, and M. Harris. 1990. Emics and etics: the insider/outsider debate. Sage, Newbury Park, California, USA.

Hickey, F. R., and R. E. Johannes. 2002. Recent evolution of village-based marine resource management in Vanuatu. SPC Traditional Marine Resource Management and Knowledge Information Bulletin 14:8-21.

Huntington, H. P. 2000. Using traditional ecological knowledge in science: methods and applications. Ecological Applications 10:1270-1274.

Jackson, J. B. C. 2001. What was natural in the coastal oceans? Proceedings of the Natural Academy of Sciences 98:5411-5418.

Johannes, R. E. 2002. The renaissance of community-based marine resource management in Oceania. Annual Review of Ecology and Systematics 33:317-340.

Kirsch, S. 2001. Lost worlds: environmental disaster, "culture loss" and the law. Current Anthropology 42:167-179.

Kramer, R. A., S. M. H. Simanjuntak, and C. Liese. 2002. Migration and fishing in Indonesian coastal villages. Ambio 31:367-372.

Kremen, C., I. Raymond, and K. Lance. 1998. An interdisciplinary tool for monitoring conservation impacts in Madagascar. Conservation Biology 12:549-563.

Loudon, J. E., M. L. Sauther, K. D. Fish, M. Hunter-Ishikawa, and Y. J. Ibrahim. 2006. One reserve, three primates: applying a holistic approach to understand the interconnections among ringtailed lemurs (Lemur catta), Verreaux's sifaka (Propithecus verreauxi), and humans (Homo sapiens) at Beza Mahafaly special reserve, Madagascar. Ecological and Environmental Anthropology 2. Available online at: http://www.u ga.edu/eea/02 2006/article05 02 2006.htm.

Mascia, M. B., J. P. Brosius, T. A. Dobson, B. C. Forbes, L. Horowitz, M. A. McKean, and N. J. Turner. 2003. Conservation and the social sciences. Conservation Biology 17:649-650.

May, R. M. 1994. Conceptual aspects of the quantification of the extent of biological diversity. Philosophical Transactions of the Royal Society of London B 345:13-20.

McCann, K. S. 2001. The diversity-stability debate. Nature 405:228-233.

Meffe, G. K., and C. R. Carroll. 1997. What is conservation biology? Pages 3-27 in G. K. Meffe, and C. R. Carroll, editors. Principles of conservation biology. Sinauer, Sunderland, Massachusetts, USA.

Nazarea, V. D. 1998. Cultural memory and biodiversity. University of Arizona, Tuscon, Arizona, USA.

Pierce Colfer, C. J., R. L. Wadley, and P. Venkateswarlu. 1999. Understanding local people's use of time: a pre-condition for good comanagement. Environmental Conservation 26:41-52.

Pollnac, R. B., B. R. Crawford, and M. L. G. Gorospe. 2001. Discovering factors that influence the success of community-based marine protected areas in the Visayas, Philippines. Ocean and Coastal Management 44:683-710.

Pullin, A. S. 2002. Conservation biology. Cambridge University Press, Cambridge, UK.

Robertson, D. P., and B. Hull. 2001. Beyond biology: toward a more public ecology for conservation. Conservation Biology 15:970-979. 
Ross, A., and K. Pickering. 2002. The politics of reintegrating Australian Aboriginal and American Indian indigenous knowledge into resource management: the dynamics of resource appropriation and cultural revival. Human Ecology 30:187-214.

Schwartzman, S., D. Nepstad, and A. Moreir. 2000. Arguing tropical forest conservation: people versus parks. Conservation Biology 14:1370-1374.

Silvano, R. A. M., and A. Begossi. 2002. Ethnoichthyology and fish conservation in the Piracicaba River (Brazil). Journal of Ethnobiology 22:285-306.

Sloan, N. A. 2002. History and application of the wilderness concept in marine conservation. Conservation Biology 16:294-305.

Song, S. J., and R. M. M'Gonigle. 2001. Science, power and system dynamics: the political economy of conservation biology. Conservation Biology 15:980-989.

Scientific Panel for Sustainable Forest Practices in Clayoquot Sound. 1995. Report 5: sustainable ecosystem management in Clayoquot Sound: planning and practices. Clayoquot Sound Scientific Panel, Victoria, British Columbia, Canada.

Stearman, A. M., and K. H. Redford. 1994. Game management and cultural survival: the Yuquí ethnodevelopment project in lowland Bolivia. Oryx 28:1-6.

Sutherland, W. J. 2003. Parallel extinction risk and global distribution of languages and species. Nature 423:276-279.

Vieitas, C. F., G. G. Lopez, and M.A. Marcovaldi. 1999. Local community involvement in conservation: the use of mini-guides in a program for sea turtles in Brazil. Oryx 33:127-131.

Warren, P. M., D. Brokensha, and L. J. Slikkerveer. 1995. Indigenous knowledge systems: the cultural dimensions of development. Intermediate Technology Publications, London, UK.

West,P. 2006. Conservation is our government now. Duke University Press, Durham, North Carolina, USA.

Wilkie, D. S., and R. A. Godoy. 2001. Income and price elasticities of bushmeat demand in lowland Amerindian societies. Conservation Biology 15:761-769.

Wilson, E. O. 2002. The Future of life. Knopff, New York, New York, USA. 